\title{
CROMOMICOSIS: REPORTE DE UN CASO INCAPACITANTE
}

\author{
Sendy Solórzano 1,2,a, Roy García ${ }^{3, a, b}$, Gustavo Hernández-Córdova²,c
}

\begin{abstract}
RESUMEN
La cromomicosis es una micosis profunda subcutánea producida por hongos dimórficos que de forma habitual habitan en restos vegetales. Se presenta el caso de un paciente de 51 años que seis años antes del ingreso se dedicaba a la fabricación de tejas en Madre de Dios, Perú; donde sufrió una lesión inicial papular en una pierna la cual se extendió hasta comprometer los cuatro miembros, con lesiones verrucosas que lo llevaron a la discapacidad. Se observaron cuerpos fumagoides en la biopsia de piel. El paciente fue hospitalizado y recibió curaciones tópicas, antibioticoterapia y terbinafina. Fue dado de alta al cabo de dos meses con mejoría clínica.
\end{abstract}

Palabras clave: Cromoblastomicosis; Cromomicosis; Micosis; Informes de casos (fuente: DeCS BIREME).

\section{CHROMOMYCOSIS: REPORT OF A DISABLING CASE}

\begin{abstract}
Chromomycosis is a deep subcutaneous mycosis caused by different dymorphic fungi species that normally live in vegetal debris. We report the case of a 51 year-old patient that six years previous to the evaluation worked making roof tiles in Madre de Dios, Peru; where he presented an initial papular lesion in a leg, which continued expanding until the 4 limbs were affected with disabling verrucous lesions. Fumagoid cells were found in the skin biopsy. The patient was hospitalized and received topical cleaning, antibiotics and terbinafine. He was discharged two months later with clinical improvement.
\end{abstract}

Key words: Chromoblastomycosis; Chromomycosis; Mycoses; Case reports (source: MeSH NLM).

\section{INTRODUCCIÓN}

La enfermedad antes llamada cromoblastomicosis, corresponde a una micosis profunda de localización subcutánea, observada por primera vez en 1911 por Pedroso en Brasil. Al no producir esporas, ni yemas o blastosporas en su vida parasitaria, la designación correcta debería ser cromomicosis ya que se distinguen por multiplicarse por facetación ${ }^{(1)}$. Desarrolla estructuras multicelulares de gruesas paredes coloreadas, llamadas células muriformes, cuerpos fumagoides, cuerpos escleróticos o de Medlar ${ }^{(1,2)}$.

El agente ingresa a través de heridas punzantes, predominantemente en miembros inferiores, ocasionalmente puede diseminarse por vía linfática, sanguínea o por autoinoculación a otras zonas del cuerpo por rascado, que puede afectar ganglios linfáticos regionales, pulmones y cerebro. El contacto con restos vegetales es el mayor factor de riesgo y puede existir susceptibilidad genética ${ }^{(1,2,3,4)}$. La evolución es crónica, con formación de nódulos y placas verrucosas, hiper o hipopigmentadas que pueden ulcerarse y dar lugar a masas tumorales papilomatosas de forma variable ${ }^{(1)}$.

Las especies más frecuentes en áreas tropicales son: Fonseca pedrosoi, Phialophora verrucosa y Cladosporium carrionii. Mientras $F$. pedrosoi predomina en la floresta húmeda; $C$. carrionii lo hace en climas secos. Aunque de predominio en América Latina, se han descrito casos en los cinco continentes ${ }^{(1,4)}$.

La lesión tisular consiste en abscesos con tejido granulomatoso y de supuración conformados por linfocitos, células plasmáticas, eosinófilos y células de Langhans. Los macrófagos no son capaces de destruir las células micóticas fagocitadas, las que siguen desarrollándose en el interior. Las células muriformes de F. pedrosoi pueden permanecer viables por más de 18 meses, después de recolectada la muestra de los pacientes. Son continuamente expelidas a la superficie de las lesiones por eliminación transepitelial a través de las fístulas ${ }^{(1,4,5)}$. Las

\footnotetext{
1 Hospital Regional del Cusco. Cusco, Perú.

2 Universidad Nacional de San Antonio Abad del Cusco. Cusco, Perú.

3 Hospital Nacional Adolfo Guevara Velasco - EsSalud. Cusco, Perú.

a Médico dermatólogo; ${ }^{b}$ Doctor en Medicina; ${ }^{c}$ Estudiante de medicina
} 


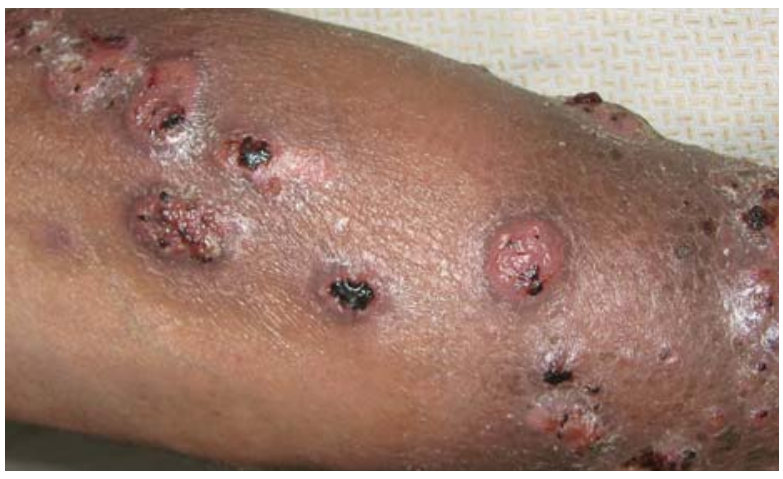

Figura 1. Compromiso amplio de una pierna con mamelones, costras y formación de placas verrucoides.

lesiones antiguas evolucionan sin tendencia a curarse espontáneamente y pueden infectarse secundariamente complicándose con linfoedema, elefantiasis y ocasionalmente carcinoma epidermoide ${ }^{(1)}$. Las dificultades para establecer el diagnóstico y los tratamientos inadecuados favorecen su evolución crónica que puede ser discapacitante como en el caso que reportamos.

El objetivo del presente reporte de caso es contribuir a su consideración dentro del diagnóstico diferencial de lesiones inflamatorias crónicas de piel y partes blandas, junto con otras micosis profundas y condiciones como Leishmaniasis, micetoma (pie de madura), lepra y tuberculosis cutánea.

\section{REPORTE DE CASO}

Paciente agricultor de 51 años de edad, procedente de Paucartambo (Cusco). Refiere que aproximadamente seis años antes del ingreso, cuando trabajaba haciendo tejas en Boca Colorado (Madre de Dios), inicia su enfermedad con una lesión papulosa y pruriginosa en pierna derecha. Progresivamente la lesión aumenta

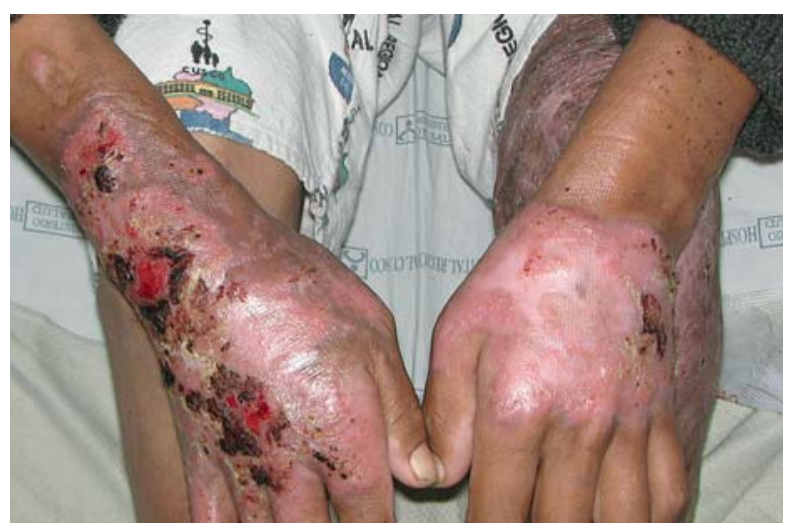

Figura 3. Compromiso amplio de las cuatro extremidades.

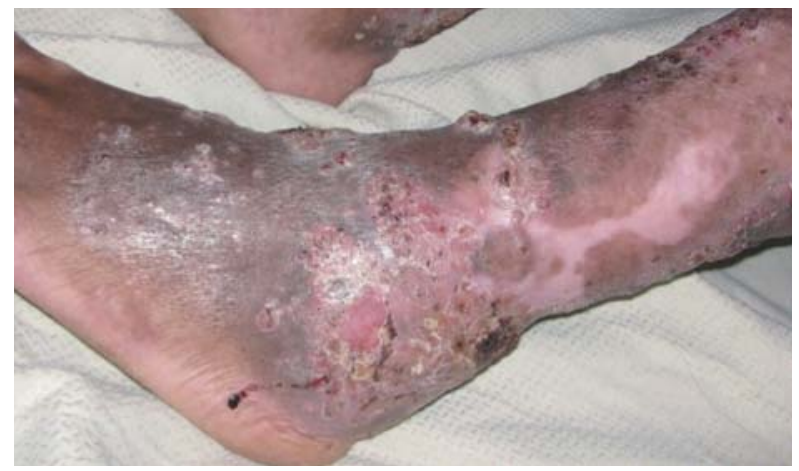

Figura 2. Deformación del pie con secuelas cicatrizales y discromías.

en extensión y dos meses después aparecen nuevas lesiones en las regiones maleolares y patelares de ambos miembros inferiores. Se agrega ardor en la zona afectada por lo que decide acudir a un centro de salud donde fue diagnosticado como Leishmaniasis, por lo que recibió tratamiento con antimoniato de meglumina por 28 días.

Ante la persistencia del cuadro, en abril de 2008 acude al Hospital Regional del Cusco por consulta externa. Se le indica internamiento y recibe tratamiento con anfotericina B durante 60 días aproximadamente. Sale por alta voluntaria. Las lesiones no mejoran y siguieron su curso hasta que el paciente presentó malestar general, sensación de alza térmica, astenia, hiporexia, ardor en miembros inferiores, prurito difuso e intenso, por lo que retorna al hospital por emergencia, decidiéndose su hospitalización en el Servicio de Infectología.

Dentro de los antecedentes de importancia refiere alcoholismo crónico. Niega otras enfermedades. Al examen físico, las funciones vitales se encontraron estables. Se evidenciaron placas verrucosas, mamelonadas, supurativas y sangrantes, malolientes, friables

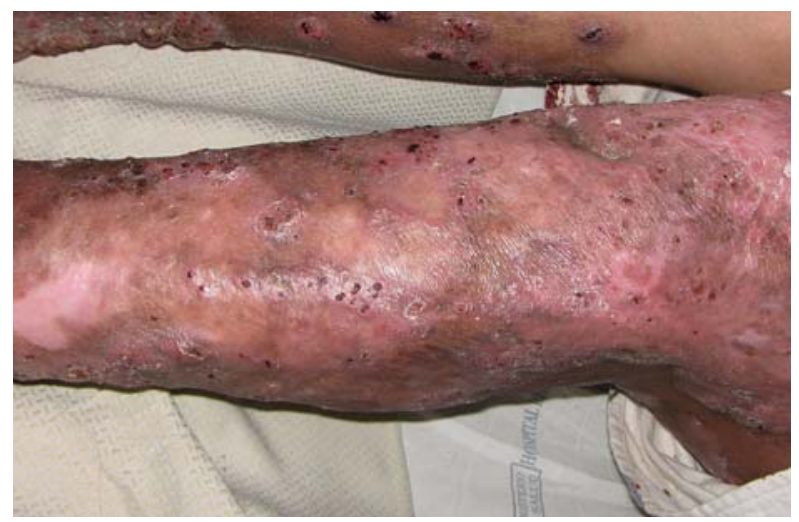

Figura 4. Combinación de lesiones activas con secuelas. 
con múltiples nódulos confluyentes y satélites cubiertos de puntos negruzcos (Figura 1), deformando extensamente los pies (Figura 2), tobillos, piernas, codos y dorso de manos (Figura 3), dejando en la evolución amplias zonas cicatrizales de aspecto esclerótico, algo retráctil en dorso de manos y principalmente en pierna izquierda (Figura 4).

El hemograma de ingreso tenía $6050 \mathrm{cel} / \mathrm{mm}^{3}$ leucocitos, $75,9 \%$ de neutrófilos; $12,3 \%$ de linfocitos; $9,3 \%$ de monocitos; $0,4 \%$ de eosinófilos; $2,1 \%$ de basófilos; hematocrito de $27,5 \%$ y hemoglobina de $9,3 \mathrm{~g} / \mathrm{dL}$. La bioquímica sanguínea mostró una glucosa de $93 \mathrm{mg} / \mathrm{dL}$, urea $25 \mathrm{mg} / \mathrm{dL}$, creatinina $0,8 \mathrm{mg} / \mathrm{dL}$, fosfatasa alcalina $148 \mathrm{U} / \mathrm{L}$ y albumina $2,9 \mathrm{~g} / \mathrm{dL}$. Una radiografía anteroposterior y lateral de miembros descartó compromiso óseo.

Se toma una biopsia de piel de tobillo cuya epidermis mostró hiperplasia pseudoepiteliomatosa y presencia de absceso neutrofílico intraepidérmico. En la dermis se evidenciaron denso infiltrado inflamatorio mixto con neutrófilos, formación de microabscesos, alternando con histiocitos reactivos y células gigantes multinucleadas. Se observaron estructuras redondeadas café dorado, anucleadas sugerentes de infección micótica. Estas células denominadas "cuerpos de Medlar" son patognomónicas de cromomicosis, aunque no indican el agente causal ${ }^{(8,12,13)}$ (Figuras 5 y 6 ).

El paciente es internado por un periodo de dos meses durante los cuales recibe curaciones y limpieza con soluciones a base de cobre, zinc y alcanfor, antibioticoterapia con dicloxacilina, ciprofloxacino el primer mes y terbinafina de $250 \mathrm{mg}$ cada doce horas las últimas tres semanas. El paciente es dado de alta en condiciones de mejoría y es citado para consulta externa.

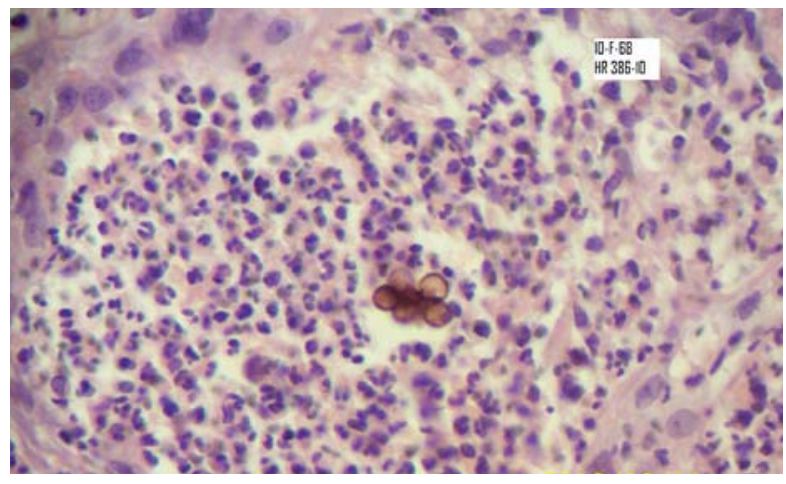

Figura 5. Biopsia con formación de microabscesos de polimorfonucleares rodeados de linfocitos e histiocitos. Tinción hematoxilina-eosina $10 \mathrm{x}$.

\section{DISCUSIÓN}

El presente es un reporte de caso de cromomicosis extensa, micosis rara en el Perú (1). Todos los casos peruanos previamente publicados han sido diagnosticados por el examen directo e histopatológico. En nuestra literatura, se ha reportado un caso atribuido a Cladosporium sp. ${ }^{(8)}$.

En este paciente no se encontró comorbilidad, puesto que no se diagnosticaron otras enfermedades sistémicas como diabetes. No obstante el recuento de linfocitos hizo necesario investigar posibles causas de inmunodeficiencia además de su alcoholismo crónico. Sin embargo, el paciente se negó a realizarse la prueba de ELISA para VIH y la serología para HTLV-1.

La respuesta a antimicóticos orales es limitada. El itraconazol $(9,11,13,14)$ o la terbinafina han sido usados como terapia única y en casos resistentes en combinación con fluocitosina o con crioterapia ${ }^{(13)}$. Desde el 2001, Esterre et al. han publicado series de casos tratados con terbinafina, $500 \mathrm{mg} /$ día por un mínimo de seis meses (y máximo doce meses) con resultados satisfactorios ${ }^{(1,6,7)}$. Junto a Guedes, también comprobaron recientemente la efectividad del tratamiento con itraconazol $200 \mathrm{mg} /$ día por al menos doce meses ${ }^{(11)}$. El voriconazol, pese a su costo elevado, también ha sido útil a la misma dosis en tres casos atribuidos a Fonsecaea pedrosoi en un reporte de Criado en Brazil (15).

En el presente caso, el antecedente epidemiológico es decisivo para la orientación del diagnóstico, así como el análisis anatomopatológico para la observación de los cuerpos fumagoides ${ }^{(1,12,13)}$; sin embargo, no se ha podido identificar la especie lo que hubiera enriquecido los hallazgos. Para nuestro medio el diagnóstico diferencial

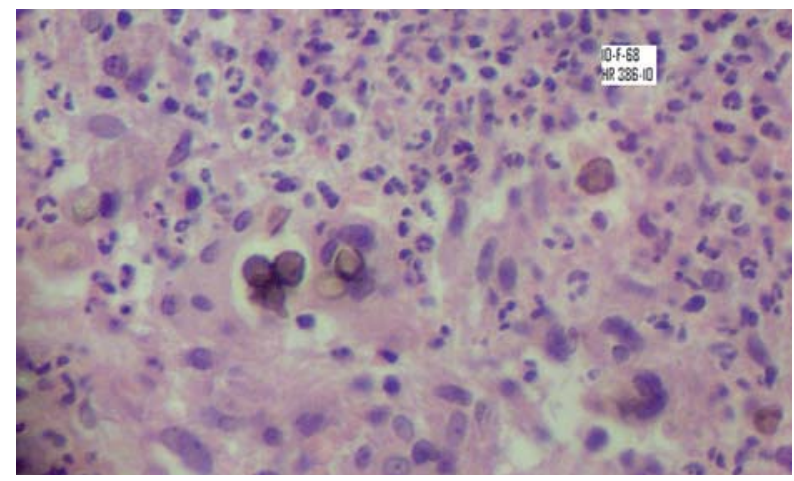

Figura 6. Reacción granulomatosa y supurativa rodeando a células micóticas de paredes gruesas parduzcas o cuerpos fumagoides. Tinción hematoxilina-eosina 40x. 
debe hacerse con tuberculosis cutánea, Leishmaniasis y esporotricosis verrucosas. ${ }^{(1,8)}$

La primera opción diagnóstica para este caso fue Leishmaniasis, que dio lugar al retraso del tratamiento del verdadero problema. Estos diagnósticos equivocados también ocurren en otros lugares como el caso reportado en Pará (Brasil) donde inicialmente trataron como lepra lepromatosa por aproximadamente 25 años a un paciente que, en los últimos dos años de forma rápidamente progresiva, presentó una cromomicosis diseminada ${ }^{(10)}$.

En cuanto a pronóstico, se reconoce que la cromomicosis no pone en peligro la vida, salvo los pocos casos de diseminación sistémica donde el pronóstico es reservado ${ }^{(10)}$. El impacto más importante ocurre por la cronicidad cuando induce a la discapacidad y por ende mella la calidad de vida, al margen del alto riesgo de desarrollar carcinoma epidermoide.

\section{AGRADECIMIENTOS}

Al patólogo Benjamín Vigo Alcántara por su colaboración para la identificación de la micosis y la toma de imágenes.

\section{Fuentes de financiamiento}

Autofinanciado.

\section{Conflictos de interés}

Los autores declaran no tener conflictos de interés en la publicación de este artículo.

\section{REFERENCIAS BIBLIOGRÁFICAS}

1. Burstein Z. Cromomicosis: clínica y tratamiento; situación epidemiológica en Latinoamérica. Rev Peru Med Exp Salud Publica. 2004;21(3):167-75.

2. Santos AL, Palmeira VF, Rozental S, Kneipp LF, Nimrichter L, Alviano DS, et al. Biology and pathogenesis of Fonsecaea pedrosoi, the major etiologic agent of chromoblastomycosis. FEMS Microbiol Rev. 2007;31(5):570-91.

3. Criado PR, Valente NYS, Brandt HRC, Belda Jr W, Halpern I. Dermatite verrucosa de Pedroso e Gomes (Cromomicose): 90 anos depois, ainda entre nos. An Bras Dermatol. $2010 ; 85(1): 104-5$.
4. Yegres NR, Yegres F. Cromomicosis: una endemia rural en la región noroccidental en Venezuela. Rev Cubana Med Trop. 2009;61(3):209-12.

5. Yegres NR, Yegres F, Pérez Blanco M. Cromomicosis en Venezuela. Santa Ana de Coro: Universidad Nacional Experimental Francisco de Miranda; 2009.

6. Hinostroza D, Padilla MC, Novales J. Cromomicosis esporotricoide. Presentación de un caso. Rev Cent Dermatol Pascua. 2004;13:21-4.

7. Esterre P, Queiroz-Telles F. Management of chromoblastomycosis: novel perspectives. Curr Opin Infect. 2006;19:148-52.

8. Cavero J, Delgado V. Cromoblastomicosis por Cladosporium sp. Folia dermatol Peru. 2004;15(1):28-31.

9. Muñoz V, Valenzuela G, Rochín M. Cromomicosis: Reporte de un caso con topografía atípica. Rev Iberoam Micol. 2011;28(1):50-2.

10. Guedes C, Pereira da Silva J, Batista da Silva M, Fagundes da Costa P, Imbiriba U. Cutaneous diffuse chromoblastomycosis. Lancet Infect Dis. 2005;5:528.

11. da Silva JP, da Silva MB, Campelo SR, Salgado UI, Diniz JA, Esterre P, et al. TGF-beta plasma levels in chromoblastomycosis patients during itraconazole treatment. Cytokine. 2010;51(2):202-6.

12. Arenas R. Cromoblastomicosis. En: Micologia Médica llustrada. 2da. ed. México: Ed. Interamericana McGraw-Hill; 2004. p. $139-47$.

13. Teixeira R, Correia M, Criado P. Cromoblastomicose: relato de 27 casos e revisão da literatura. An Bras Dermatol. 2010;85(4):448-54.

14. Flores $Y$, Carreño R. Cromomicosis en área no endémica de Venezuela. CIMEL. 2010;15(1):43-5.

15. Criado PR, Careta MF, Valente NY, Martins JE, Rivitti EA, Spina R, et al. Extensive long-standing chromomycosis due to Fonsecaea pedrosoi: Three cases with relevant improvement under voriconazole therapy. J Dermatolog Treat. 2011;22(3):167-74.
Correspondencia: Sendy Solórzano

Facultad de Medicina Humana, Universidad Nacional de San Antonio Abad de Cusco

Dirección: Av. de la Cultura s/n. Cusco, Perú.

Teléfono: (051) 997-880340

Correo electrónico: ydnessan@hotmail.com 